\title{
Analisis pelaksanaan clinical pathway di RSUP Prof. Dr. R. D. Kandou Manado
}

\author{
${ }^{1}$ Cicilia Paat, ${ }^{2}$ Erwin Kristanto, ${ }^{3}$ Flora P. Kalalo
}

\author{
${ }^{1}$ Program studi Ilmu Kesehatan Masyarakat Bidang Minat Kajian Administrasi Rumah Sakit \\ Pascasarjana Universitas Sam Ratulangi Manado \\ ${ }^{2}$ Fakultas Kedokteran Universitas Sam Ratulangi Manado \\ ${ }^{3}$ Fakultas Hukum Universitas Sam Ratulangi Manado \\ Email: ciciliapaat1@gmail.com
}

\begin{abstract}
Clinical pathway is a significant administration document to achieve the good clinical governance in the hospital. In Indonesia, this document is one of the very critical requirements that should be provided by the hospital to fulfil the KARS 2012 policy. As the center of referral teaching hospital of East Indonesia, Professor Dr. R. D. Kandou General Hospital has committed to fulfil the international standard of care, inter alia implementation of the clinical pathways based on the main cause of death, high risk, and high cost. There are several obstacles concerning this implementation, such as the irresponsibility of the doctors due to overloaded work, lack of concentration in filling the formation of clinical pathway, and uncertainity in the usage of clinical pathway. This study was aimed to evaluate the implementation of the clinical pathway and its limitation in the hospital above. The results showed that the administrative policy of the clinical pathway had been provided by the top management leader with the specialization in dengue shock syndrome (DSS), chronic kidney disease (CKD), eclampsia, benign prostatic hypertrophy (BPH), and myocardial infarction (MCI) without complication. Conclusion: Clinical pathway was implemented at Prof. Dr. R. D. Kandou General Hospital according to the Minister Health Regulation No. 012 Year 2012 about Standard Accreditation for Hospital.
\end{abstract}

Keywords: clinical pathway, hospital

\begin{abstract}
Abstrak: Clinical pathway merupakan bagian penting dari dokumen dan alat dalam mewujudkan good clinical governance di rumah sakit. Di Indonesia, dokumen ini juga menjadi salah satu syarat yang harus dipenuhi dalam Standar Akreditasi Rumah Sakit versi KARS 2012. Rumah Sakit Prof. Dr. R. D. Kandou merupakan rumah sakit pendidikan dan pusat rujukan untuk wilayah Indonesia Timur, berkomitmen untuk meningkatkan pelayanan berstandar internasional; salah satu upayanya dengan mengimplementasikan clinical pathway. Pemilihan clinical pathway ditujukan pada penyakit-penyakit yang merupakan penyebab utama kematian, berisiko tinggi, dan biaya tinggi. Kendala penggunaan clinical pathway antara lain kurangnya kepatuhan dokter penanggung jawab pasien terhadap clinical pathway, kurangnya konsentrasi dalam pengisian pembentukan clinical pathway, serta kesulitan kepastian penggunaan clinical pathway. Penelitian ini bertujuan untuk mengetahui pelaksanaan clinical pathway dan analisis terhadap kendala-kendalanya di RSUP Prof. Dr. R. D. Kandou Manado. Hasil studi menunjukkan bahwa pada tingkat manajerial telah tersedia kebijakan clinical pathway dan spesialisasinya yaitu dengue shock syndrome (DSS), penyakit ginjal kronik (PGK), preeklamsia berat, benign prostat hypertrophy (BPH), dan miokard cardiac infark (MCI) tanpa komplikasi. Simpulan: Clinical pathway telah diterapkan di RSUP Prof. Dr. R. D. Kandou berdasarkan Permenkes Nomor 012 tahun 2012 tentang Standar Akreditasi Rumah Sakit.
\end{abstract}

Kata kunci: clinical pathway, rumah sakit 
Rumah sakit berkewajiban memberikan pelayanan kesehatan yang aman, bermutu, anti diskriminasi, dan efektif dengan mengutamakan kepentingan pasien sesuai dengan standar pelayanan rumah sakit. Tujuan yang paling utama dalam pelayanan kesehatan ialah menghasilkan outcome yang menguntungkan pasien, provider, dan masyarakat. Pencapaian outcome yang diinginkan sangat bergantung dari mutu pelayanan kesehatan/rumah sakit. ${ }^{1}$

Salah satu upaya penting yang dilakukan oleh Kementrian Kesehatan ialah pembuatan standar pelayanan. Saat ini sektor kesehatan melengkapi peraturan perundang-undangannya dengan disahkannya Undang-Undang No. 29 tahun 2004 tentang Praktik Kedokteran. ${ }^{2}$ Di tingkat nasional diperlukan penyusunan Pedoman Nasional Pelayanan Kedokteran (PNPK) yang berisi pernyataan yang sistematis, mutakhir, dan evidence based untuk membantu dokter/pemberi jasa layanan lain dalam menangani pasien dengan kondisi tertentu. Karena sifatnya yang canggih dan mutakhir, maka PNPK harus diterjemahkan menjadi Panduan Praktik Klinis (PPK) oleh masing-masing fasilitas pelayanan kesehatan (fasyankes) sesuai dengan keadaan setempat. PPK dapat disertai perangkat pelaksanaan langkah demi langkah termasuk clinical pathway. ${ }^{3}$

Clinical pathway merupakan bagian penting dokumen dan alat dalam mewujudkan good clinical governance di rumah sakit. Di Indonesia, dokumen ini juga menjadi salah satu syarat yang harus dipenuhi dalam Standar Akreditasi Rumah Sakit versi KARS 2012. ${ }^{4}$ Menjadi pertanyaan besar dalam penyelenggaraan pelayanan kesehatan di rumah-rumah sakit di Indonesia ialah bagaimana agar clinical pathway dapat berperan secara optimal dalam kendali mutu dan kendali biaya di rumah sakit serta bukan hanya sekedar dokumen kertas yang menjadi prasyarat akreditasi.

Tantawi et al. ${ }^{5}$ meneliti tentang clinical pathway versus traditionl care plan for caring post operative children undergoing cardiothoracic surgery. Hasil penelitiannya menunjukkan setelah dilakukan penerapan clinical pathway terdapat perbaikan yang nyata terhadap pengetahuan dan kinerja dari hampir semua perawat. Para perawat dan dokter memperoleh pengetahuan yang baik tentang clinical pathway dan tingkat kepuasan pasien meningkat.

Rumah Sakit Prof. Dr. R. D. Kandou merupakan rumah sakit pendidikan dan pusat rujukan untuk wilayah Indonesia Timur dan berkomitmen untuk meningkatkan pelayanan berstandar internasional. Salah satu upaya untuk meningkatkan pelayanan dan keseragaman pelayanan yaitu dengan mengimplementasikan clinical pathway. Terdapat 5 clinical pathway yang pertama kali diimplentasikan di RSUP Prof. Dr. R. D. Kandou, yaitu clinical pathway dengue shock syndrome (DSS), penyakit ginjal kronik (PGK), preeklamsia berat, benign prostat hypertrophy (BPH), dan miokard infark akut (MCI) tanpa komplikasi. Pemilihan clinical pathway ini dikarenakan penyakitpenyakit tersebut merupakan penyebab utama kematian, berisiko tinggi, dan biaya tinggi. $^{6}$

Berdasarkan latar belakang di atas, penulis ingin mengkaji lebih lanjut mengenai implementasi clinical pathway di RSUP Prof. Dr. R. D. Kandou dengan tujuan menganalisis penyusunan, pelaksanaan, pengawasan serta evaluasi clinical pathway di RSUP Prof. Dr. R. D. Kandou.

\section{METODE PENELITIAN}

Penelitian ini dilakukan dengan menggunakan metode kualitatif yang bertujuan untuk mendapatkan informasi yang lebih mendalam melalui analisis pelaksanaan clinical pathway di RSUP Prof. Dr. R. D. Kandou. Penelitian ini dilakukan di RSUP Prof. Dr. R. D. Kandou pada bulan Oktober sampai dengan Desember 2016. Pengumpulan data dilakukan dengan cara wawancara mendalam terhadap 7 informan yang terdiri dari: dokter, manajemen pelayanan medik rawat inap, Komite Peningkatan Mutu dan Keselamatan Pasien, dan perawat. 
Pemilihan sampel pada penelitian ini berdasarkan prinsip kesesuaian (appropriateness) dan kecukupan (adequency). Validasi hasil penelitian dengan cara triangulasi sumber dan triangulasi teknik.

\section{HASIL PENELITIAN DAN BAHASAN Kebijakan manajemen}

Kebijakan dari Departemen Kesehatan bahwa pola pembiayaan kesehatan di rumah sakit menggunakan sistem INADRG melalui surat edaran Menteri Kesehatan Nomor 568/Menkes/VII/2008. Agar hal ini dapat berjalan dengan baik, rumah sakit harus melaksanakan pelayanan sesuai dengan clinical pathway. Salah satu elemen yang terkait ialah rumah sakit harus membuat perencanaan perawatan pasien sebelum pasien dirawat yang merupakan integrasi dari berbagai standar medik, keperawatan, farmasi, dan penunjang (clinical pathway). Penerapan clinical pathway ini sangat memerlukan dukungan rumah sakit dalam bentuk kebijakan. Tanpa adanya dukungan kebijakan dari manajemen maka clinical pathway tidak akan bisa terlaksana karena kebijakan di sebuah rumah sakit merupakan dasar hukum untuk pelaksanaan suatu program. ${ }^{7}$

Dari hasil wawancara mendalam dan observasi dokumen di RSUP Prof Dr. R. D Kandou dapat disimpulkan bahwa pihak manajemen sangat mendukung pelaksanaan clinical pathway. Hal ini tampak dari telah adanya Surat Keputusan Direktur dan dalam pelaksanaannya sudah didukung dengan kebijakan operasional berupa prosedur tetap implementasi clinical pathway.

\section{Penyusunan clinical pathway}

Berdasarkan hasil penelitian di RSUP Prof Dr. R. D. Kandou, diketahui bahwa dalam penyusunan format clinical pathway telah sesuai dengan komponen yang harus tercakup sebagaimana definisi clinical pathway. Hal ini sejalan dengan temuan penelitian yang dilakukan oleh Firmanda ${ }^{8}$ bahwa dalam menyusun format clinical pathway dengan memperhatikan komponen yang harus dicakup sebagaimana definisi dari clinical pathway. Tim penyusun clinical pathway di RSUP Prof. Dr. R. D. Kandou ialah dari masing-masing kelompok staf medis (KSM) yang disesuaikan dengan Pedoman Praktik Klinis (PPK) yang ada. Prioritas pemilihan clinical pathway yang digunakan ialah high risk, high volume, high cost, dan problem prone. ${ }^{9}$ Hal ini sejalan dengan hasil penelitian yang dilakukan oleh Romeyke dan Stummer ${ }^{10}$ bahwa penyusunan clinical pathway bagi penyedia layanan terdapat pada tingkat proses inti (dokter spesialis, perawat, terapis dan staf keperawatan).

\section{Sosialisasi clinical pathway oleh manajemen rumah sakit}

Berdasarkan hasil wawancara mendalam dengan beberapa informan didapatkan bahwa pihak RSUP Prof Dr. R. D. Kandou telah melakukan upaya edukasi (pendidikan dan pelatihan) kepada staf dalam rangka penerapan clinical pathway ini. Sosialisasi clinical pathway pada umumnya dilaksanakan di saat menjelang proses akreditasi rumah sakit karena clinical pathway merupakan salah satu unsur dalam peningkatan mutu dan keselamatan pasien yang juga merupakan kriteria penilaian akreditasi rumah sakit. Bentuk sosialisasi clinical pathway dilakukan secara gabungan antara semua pihak yang terlibat seperti dokter penanggung jawab pelaksana (DPJP), dokter ruangan, dan perawat yang biasanya dilakukan dalam waktu relatif lama.

Sejak dimulainya akreditasi rumah sakit, RSUP Prof. Dr. R. D. Kandou tahun 2015 telah memulai membuat konsep clinical pathway. Dalam perkembangan selanjutnya telah dilakukan edukasi dalam bentuk pelatihan di rumah sakit dengan mengadakan workshop maupun dengan mengirim petugas mengikuti pelatihan dan seminar clinical pathway yang diadakan Kementrian Kesehatan. Dalam penerapan edukasi pada tingkat operasional telah dilakukan di bagian SMF masing-masing dengan mengupdate perkembangan clinical pathway ini. Bagian keperawatan sudah 
mulai menghitung berapa sumber daya bahan habis pakai yang digunakan pasien dalam penerapan clinical pathway ini. Jadi pihak manjemen dan staf telah menyadari pentingnya edukasi bagi staf untuk clinical pathway ini. Hal ini sesuai dengan teori yang menyatakan bahwa edukasi dan komunikasi yang intensif dibutuhkan untuk menjamin clinical pathway dapat berjalan dengan baik. ${ }^{11}$

\section{Penggalangan komitmen dan kepatuhan}

Berdasarkan hasil wawancara mendalam dengan informan didapatkan bahwa di RSUP Prof Dr. R. D. Kandou telah dilakukan penggalangan komitmen manajemen dan staf untuk penerapan clinical pathway dengan cara pertemuan berkala oleh pihak manajemen meskipun dalam kenyataannya pertemuan tersebut awalnya hanya dilakukan menjelang akreditasi rumah sakit. Penelitian Nurfaida $^{12}$ tentang penerapan clinical pathway melalui studi kasus di Instalasi Gawat Darurat Rumah Sakit Umum Dr. Saiful Anwar Malang Jawa Timur menyimpulkan bahwa belum adanya komitmen dokter, kepemimpinan klinis, dan dukungan manajemen klinis merupakan hal yang menghambat penerapan clinical pathway. Komitmen adalah upaya penyatuan persepsi dan kesepakatan, serta tekad bersama untuk mencapai sebuah tujuan. ${ }^{7}$ Pembentukan komitmen organisasi sangat diperlukan dalam penerapan clinical pathway di rumah sakit. ${ }^{11}$

\section{Penerapan clinical pathway}

Berdasarkan hasil wawancara mendalam dengan informan diketahui bahwa clinical pathway telah diterapkan di RSUP Prof Dr. R. D. Kandou. Salah satu manfaat penting penyelenggaraan clinical pathway ialah mutu pelayanan kesehatan menjadi lebih baik, adanya kepastian rencana untuk tata laksana pasien, mengurangi length of stay pasien, dan mengontrol biaya. Secara umum hal itu berarti mengurangi beban biaya rumah sakit maupun membuka peluang bagi pasien lain untuk masuk ke rumah sakit. Turn over yang cepat dengan length of stay yang relatif rendah akan dengan sendirinya membuka akses luas bagi penerima manfaat layanan kesehatan lainnya. Seperti disebutkan oleh Zhang, ${ }^{13}$ Milne et al,${ }^{14}$ dan Frei et al. ${ }^{15}$ bahwa penggunaan clinical pathway dapat meningkatkan efisiensi dan kualitas, mengontrol biaya pelayanan kesehatan, serta mengurangi komplikasi dan lama rawat inap. Selanjutnya hasil penelitian dari Huang et al. ${ }^{16}$ menunjukkan manfaat penerapan clinical pathway yaitu dapat mengurangi rerata lama rawat inap, mengurangi pengeluaran rawat inap, meningkatkan kepuasan pasien, dan meningkatkan kualitas pelayanan dalam manajemen stroke. Temuan penelitian yang pernah dilakukan Romeyke and Stummer ${ }^{10}$ menunjukkan bahwa dengan cara indikasi dan perencanaan pengembangan prosedur terkait, clinical pathway membantu dokter, perawat, dan terapis sebagai alat untuk sosialisasi dan evaluasi proses pengobatan.

\section{Hambatan penerapan clinical pathway}

Pelaksanaan clinical pathway di RSUP

Kandou secara umum tidak menghadapi hambatan-hambatan; berarti, baik secara personal (dokter) maupun dukungan dari segi manajemen dan sistem yang berlaku di RSUP Prof Dr R.D. Kandou. Pada kenyataan dalam pelaksanaan clinical pathway terkait dengan pengisian kelengkapan di rekam medik. Sebagai contoh, pengisian lembar lain di catatan perkembangan pasien terintegrasi kadang kala tidak ada atau tidak sesuai dengan clinical pathway yang ada padahal hal tersebut terkait kepatuhan pengisian berkas di rekam medik. Namun, laporan rekapitulasi rekam medik cenderung menunjukkan hasil audit yang lengkap sudah dengan data clinical pathway. Hal ini terjadi ketika dalam proses pemeriksaan pelaksanaan clinical pathway, petugas rekam medik yang bertanggung-jawab memanggil dokter yang bersangkutan untuk melengkapi clinical pathway di rekam medik. Kendala penerapan clinical pathway menurut hasil penelitian dari 
Zannini et al. ${ }^{17}$ ialah clinical pathway meningkatkan beban kerja birokrasi dan masalah dapat timbul dalam hubungan antara dokter dan otoritas kesehatan daerah. Aspek manajerial harus dipertimbangkan dengan hati-hati dalam rangka memperkenalkan clinical pathway di praktek umum dan kelangsungannya harus dijamin untuk meningkatkan kepatuhan dan komitmen dokter.

\section{Evaluasi/pengawasan clinical pathway}

Pengawasan clinical pathway di RSUP Prof Dr R. D. Kandou dilakukan oleh Komite Peningkatan Mutu dan Keselamatan Pasien (PMKP) yang dalam proses akreditasi dianggap bertanggung jawab terhadap pelaksanaan dan pengawasan clinical pathway di rumah sakit. Hal ini sejalan dengan penelitian yang dilakukan oleh Chew et al. ${ }^{18}$ bahwa clinical pathway terpadu mendasari proses rehabilitasi secara keseluruhan dan digunakan sebagai rencana perawatan interdisipliner untuk seluruh tim rehabilitasi; jadi, pelaksanaan clinical pathway merupakan tanggung jawab bersama seluruh tim rehabilitasi. Dalam beberapa kajian mengenai pelaksanaan evaluasi dari clinical pathway memang tidak terlalu banyak pembahasan yang menyangkut tanggung-jawab komite medik. Tidak berfungsinya komite medik dalam melaksanakan tugasnya dibidang ini bisa disebabkan keterbatasan tenaga maupun sistem yang belum dibangun.

Di RSUP Prof Dr. R. D. Kandou evaluasi dan pengawasan dalam pelaksanaan clinical pathway dilakukan secara berkala dan berkelanjutan. Setiap awal tahun dilakukan evaluasi pelaksanaan clinical pathway dalam rapat-rapat yang melibatkan kelompok staf medis (KSM), komite PMKP serta staf rumah sakit yang berkaitan. Hasil penelitian dari Romeyke dan Stummer ${ }^{19}$ menyatakan bahwa untuk manajemen bisnis dari rumah sakit, clinical pathway menyajikan instrumen manajemen strategis yang juga berfungsi sebagai instrumen untuk terus-menerus pengendalian biaya dan dapat berkontribusi untuk transparansi dalam penyediaan layanan.

\section{SIMPULAN}

Dari hasil penelitian dan bahasan dapat disimpulkan bahwa:

1. Penyusunan clinical pathway secara teknis ialah dari masing-masing kelompok staf medis (KSM) yang disesuaikan dengan Pedoman Praktik Klinis (PPK) yang ada dan dikoordinasi oleh komite medik. Prioritas pemilihan clinical pathway berdasarkan jumlah kasus yang banyak (high volume), mempunyai risiko tinggi (high risk) serta cenderung memerlukan biaya tinggi/banyak sumber daya (high cost).

2. Clinical pathway telah diterapkan di RSUP Prof. Dr. R. D. Kandou Manado sejak tahun 2015 sebagaimana standar akreditasi rumah sakit berdasarkan Permenkes Nomor 12 tahun 2012 tentang akreditasi rumah sakit. Clinical pathway di RSUP Prof. Dr. R.D. Kandou terdiri dari 5 jenis yaitu clinical pathway Dengue Shock Syndrome (DSS) pada bagian anak, Penyakit Dalam dengan Penyakit Ginjal Kronik (PGK), Obstetri Ginekologi dengan Preeklampsia Berat, Bedah dengan penyakit Benign Prostat Hipertrophy (BPH) dan Kardiologi dengan Miokard Infark Akut (MCI) tanpa komplikasi.

3. Pengawasan pelaksanaan clinical pathway dilakukan oleh penanggung jawab/manajemen rumah sakit dan Komite PMKP (Peningkatan Mutu dan Keselamatan Pasien). Pengawasan dilakukan secara berkala dan berkelanjutan setiap 3 bulan.

\section{SARAN}

1. Untuk RSUP Prof. Dr. R. D. Kandou: Clinical pathway yang telah dibuat sebagaimana Peraturan Pemerintah dan standar Akreditasi Rumah Sakit hendaknya diteruskan dan dievaluasi untuk diperbaiki sehingga terdapat pengendalian mutu dan biaya. Selain itu, perlu dioptimalkan peran tim mutu Komite Medik dalam mendukung 
pelaksanaan clinical pathway.

2. Untuk Institusi Pendidikan: diharapkan dapat melakukan penelitian lanjutan tentang analisis dampak penggunaan clinical pathway terhadap biaya perawatan apakah sesuai dengan tarif INA-CBGs.

\section{DAFTAR PUSTAKA}

1. Hatta GR. Pedoman Manajemen Informasi Kesehatan di Sarana Pelayanan Kesehatan. Jakarta: UI-Press, 2010.

2. Undang-Undang Republik Indonesia Nomor 29 tentang Praktik Kedokteran. Jakarta, 2004.

3. Pedoman Penyusunan Standar Pelayanan Kedokteran. Jakarta: Konsorsium Upaya Kesehatan Direktorat Jendral Bina Upaya Kesehatan Kementrian Kesehatan Republik Indonesia, 2014.

4. Standar Akreditasi Rumah Sakit. Jakarta: Kementrian Kesehatan Republik Indonesia, 2012.

5. Tantawi HR, Lotfy I, Abdallh A, Sadek BN. Clinical pathway versus traditional care plan for caring post operative children undergoing cardio thoracic surgery. Life Sci J. 2015;12(7):41-62.

6. Buku Saku Panduan Akreditasi Revisi B. Manado: RSUP Prof. Dr. R. D. Kandou, 2016.

7. Devitra A. Analisis implementasi clinical pathway kasus stroke berdasarkan INA-CBGs di Rumah Sakit Stroke Nasional Bukit Tinggi. Padang: Universitas Andalas; 2011.

8. Firmanda D. Clinical pathways kesehatan anak. Sari Pediatri. 2006;8(3):195208.

9. Wijayanti FER, Lamsudin R, Wajdi F. Analisis clinical pathway dengan BPJS antara RS negeri dan RS swasta. Surakarta: Universitas Muhammadiyah Surakarta; 2016.

10. Romeyke T, Stummer H. Clinical pathway as instruments for risk and cost management in hospitals. GJHS. 2012;4(2). DOI: $10.5539 /$ gjhs. $\mathrm{v} 4 \mathrm{n} 2 \mathrm{p} 50$.
11. Cheah J. Development and implementation of a clinical pathway programme in an acute general hospital in Singapore. Int J Qual Health Care. 2000;12(4):403-12.

12. Nurfaida S. Peranan budaya organisasi dalam kesiapan penerapan clinical pathway. Malang, 2009. Available from: htttp: //Jurnal Manajemen Pelayanan Kesehatan. 2010.

13. Zhang M. The application and practice of the electronic clinical pathway. J Transl Med. 2012;10(2):A57. DOI: 10.1186/1479-5876-10-S2-A57.

14. Milne T, Rogers J, Kinnear E, Martin H, Lazzarini $P$, Quinton $T$, et al. Developing an evidence based clinical pathway for the assesment, diagnosis and management of acute Charcot neuro-arthropathy. J Foot Ankle Res. 2013;6(1):10. DOI: 10.1186/1757-1146-6-S1-P10.

15. Frei CR, Bell AM, Traugott KA, Jaso TC, Daniels KR, Mortensen EM, et al. A clinical pathway for communityacquired pneumonia: an observational cohort study. BMC Infect Dis. 2011;11:88. DOI: 10.1186/1471-233411-188.

16. Huang D, Song X, Tian J, Cui Q, Yang K. Effects of clinical pathways in stroke management: a meta-analysis. Neurol Asia. 2015;20(4):335-42.

17. Zannini L, Cattaneo C, Peduzzi $P$, Lopiccoli S, Auxilia F. Experimenting clinical pathway in general practice: a focus group investigation with Italian general practitioners. J Public Health Res. 2012;1(30):192-8.

18. Chew DD, Brook KS, Silvagni H. Evaluation of a generic integrated care pathway for rehabilitation. Aus J Adv Nurs. 2007;25(2):62-9.

19. Romeyke T, Stummer H. High quality at low cost - How can a clinical pathway contribute towards reconciling this apparent contradiction? IOSRPHR. 2012;2(6):10-20. 